J. Lake Sci. (湖泊科学), $2006, \mathbf{1 8}(4): 395-400$

http:// www. jlakes. org. E-mail: jlakes@ niglas. ac.cn

(c) 2006 by Journal of Lake Sciences

\title{
太湖上游流域农业土地的氮剩余及其对湖泊富营养化的影响“
}

\author{
许朋柱 ${ }^{1}$, 秦伯强 ${ }^{1}$, Horst Behrendt ${ }^{2}$, 黄文钰 ${ }^{1}$, 于树梅 ${ }^{1}$, 章永鹏 ${ }^{1}$ \\ (1: 中国科学院南京地理与湖泊研究所,南京 210008) \\ (2: 德国淡水生态与内陆渔业研究所,柏林 D - 12587)
}

\begin{abstract}
摘 要:太湖上游流域农业土地中氮的剩余对太湖的富营养化具有至关重要的影响. 利用 2002 年各乡镇的农业统计资 料,对上游流域农业土地中氮的剩余量进行计算. 计算结果表明, 上游流域农业土地中氮的剩余总量为 $134.8 \times 10^{3} \mathrm{t} / \mathrm{a}$, 单位农业土地面积的剩余量为 $178.9 \mathrm{~kg} /\left(\mathrm{hm}^{2} \cdot \mathrm{a}\right)$. 从单位面积氮剩余量的空间变化看,东、西苕溪流域的剩余量较低, 而其它流域的剩余量相对较高. 借助典型区域氮剩余的长系列计算数据, 对上游地区氮剩余的长期变化规律进行分析. 并在此基础上,探讨太湖的富营养化演变趋势与氮剩余长期变化的关系.
\end{abstract}

关键词:太湖上游; 农业土地; 氮的剩余量; 富营养化

\section{Nitrogen surplus of the upstream agricultural land of Lake Taihu and the eutrophication impact}

XU Pengzhu ${ }^{1}$, QIN Boqiang ${ }^{1}$, HORST Behrendt ${ }^{2}$, HUANG Wenyu ${ }^{1}$, YU Shumei $^{1}$ \& ZHANG Yongpeng ${ }^{1}$

(1: Nanjing Institute of Geography and Limnology, Chinese Academy of Sciences, Nanjing 210008, P. R. China)

(2: Leibniz Institute of Freshwater Ecology and Inland Fisheries, Berlin D-12587, Germany)

Abstract: The nitrogen surplus of the upstream agricultural land have a great impact on the eutrophication of the Lake Taihu. Based on the suburban agricultural data of the year 2002, the nitrogen surplus was calculated for the agricultural land of the upstream Taihu. The calculation results show that the agricultural land has a total surplus of $134.8 \times 10^{3} \mathrm{t} / \mathrm{a}$, and the kilogram surplus per hectare agricultural land is $178.9 \mathrm{~kg}$ per year. The east and west Tiaoxi catchments have lower surplus values less than $130 \mathrm{~kg} /\left(\mathrm{hm}^{2} \cdot \mathrm{a}\right)$, but the other regions have higher values. According to the long calculated series of the $\mathrm{N}$-surplus in the case-study region, the long-term $\mathrm{N}$-surplus changes for the whole upstream area of the Lake Taihu are analyzed in the paper. At last, the authors discuss the relationship of the eutrophication trend of the Lake Taihu and N-surplus changes in the upstream agricultural land.

Keywords: The upstream of the Lake Taihu; agricultural land; nitrogen surplus; eutrophication

氮是农作物生长必不可少的营养物质, 农作物产量的高低与农田中氮含量的高低具有高度的相关性. 自人工合成肥料出现以来,农田中氮的原有平衡受到破坏,并构建起新的平衡. 农田中输人的氮除被植物 吸收外,剩余量将进入地表、地下水体或蓄积及损失于土壤中.

近年来, 随着水污染的加剧, 人们开始关注农业非点源污染的问题. 关于点源与面源的贡献问题,一直 是环境科学工作者争论的焦点问题. 在河湖富营养化比较严重的地区, 人们至今还不能十分正确地估算出 农田中排放出来的氮(或者说估算结果还有偏差). 其后果是为河湖的富营养化治理带来困难.

农业土地氮剩余量的计算是农业面源氮排放量计算的基础. 自上世纪 90 年代末期,许多发达国家的 环境学家通过对农业土地的氮剩余量的估算, 开展氮排放量的模拟研究, 制定出农业面源营养盐的管理策 略. 例如, 在欧洲莱茵河流域及多瑙河流域的沿岸国家, 均已开展农业土地的氮剩余研究 ${ }^{[1-4]}$. 在国内, 这 
方面的研究工作还较少开展. 本项研究选择太湖上游流域为典型研究区域, 以乡镇农业数据为主要数据 源, 在建立区域农业土地氮平衡模型的基础上, 计算农业土地的氮剩余量. 然后, 根据推算的氮剩余的长期 变化趋势, 探讨太湖富营养化演化的成因.

\section{1 材料与方法}

\section{1 区域农业土地的氮平衡方程}

根据联合国经济合作与发展组织 ${ }^{[5]}$ 的定义, 每年进人土壤的营养盐输人量与作物吸收脱离土壤的营 养盐输出量之间存在一定的差额, 该差额定义为剩余量 (或缺失量). 根据以上定义, 建立如下的区域农业 土地的氮平衡模型:

$$
N_{\text {Surplus }}=N_{\text {Input }}-N_{\text {Output }}, N_{\text {Input }}=\sum_{k=1}^{m} I_{i} /(A \times 1000), N_{\text {Output }}=\sum_{j=1}^{n} O_{j} /(A \times 1000)
$$

式中, $N_{\text {Input }} 、 N_{\text {Output }} 、 N_{\text {Surplus }}$ 分别为某一行政区域内单位农业土地面积的氮的输人量、输出量及剩余量, 单位 为 $\mathrm{kg} /\left(\mathrm{hm}^{2} \cdot \mathrm{a}\right) ; I_{\mathrm{i}}$ 为 $\mathrm{m}$ 个输人来源的氮的输人总量, 单位为 $\mathrm{t} / \mathrm{a} ; \mathrm{O}_{\mathrm{j}}$ 为 $n$ 个输出途径的氮的输出总量, 单位 为 $\mathrm{t} / \mathrm{a} ; A$ 为行政区域的农业土地面积,包括耕地、园地及草地,单位为 $\mathrm{hm}^{2}$.

\section{2 氮的的输入量计算}

农业土地中氮的来源途径非常多, 其中化肥及动物粪便是最主要的来源方式, 除此以外, 大气干湿沉 降、生物固氮、河湖淤泥及污水处理厂污泥的再生利用等也是农田中氮的输人来源. 以区域统计年鉴中的 农业统计资料为主要的基础资料, 对各种途径氮的输人量进行统计计算, 并最终汇总出各个行政单元的氮 的总输人量.

来源于化肥的氮的输人量直接根据统计年鉴中各行政单元的氮肥的折纯量及复合肥中的全氮比重进 行统计计算. 对于缺少化肥统计资料的行政单元,采用农业发展水平相当的相邻地区的单位面积化肥使用 量资料.

人畜粪便产生的氮也是农业土地中氮的主要输人量. 利用统计年鉴中各行政单元的农业人口及畜禽 统计数量, 乘以各种人及畜禽的单位排放系数, 计算出人及各种畜禽的氮的产出量, 最后, 汇总计算出行政 单元的人畜粪便的氮输人量. 根据动物的类别、品种、性别、年龄、用途以及饲养方式的不同, 参考有关文 献 ${ }^{[1,2]}$, 确定单位排放系数. 本研究确定的几个主要类别的排放系数为: 牛 $20.2-78.6 \mathrm{~kg} /($ 头・ a ), 猪 3.5 $-20.9 \mathrm{~kg} /($ 头 $\cdot a)$, 羊 $5.1-9.8 \mathrm{~kg}$ / (头・a), 鸡 $0.3-0.6 \mathrm{~kg}$ / (头・a), 鸭 $1.0-1.4 \mathrm{~kg}$ / (头・a), 兔 1.0 $\mathrm{kg} /($ 头 $\cdot \mathrm{a})$. 牛、猪排放系数的高值适用于优良品种的成年雌体动物, 而低值为这两种动物幼体的排放系 数. 农民家养土鸡的排放系数采用低值, 而养鸡场鸡的排放系数采用高值. 对于其它动物, 根据单体平均体 重与类似动物的差异, 将其数量折算成类似动物的数量. 统计资料中缺少的有关动物品种、性别、年龄、用 途等方面的资料, 通过样本调查获取. 考虑到人畜粪便大约有 $30 \%$ 以上的氨氮被挥发掉 ${ }^{[1]}$, 对计算结果进 行修正.

农业土地面积乘以单位面积的纯氮沉降量, 得到通过大气沉降输人到农田中的氮. 大气沉降数据来源 于当地环境监测站的环境监测数据.

农业土地的生物固氮包括豆科植物的生物固氮及土壤生物的生物固氮两个方面. 利用不同种类豆科 植物收获面积及固氮系数, 将两者相乘, 到豆科植物的固氮量. 豆科植物的固氮系数 $25-240 \mathrm{~kg} /\left(\mathrm{hm}^{2} \cdot \mathrm{a}\right)$ N. 单位面积土壤生物的固氮量取值 $25 \mathrm{~kg} /\left(\mathrm{hm}^{2} \cdot \mathrm{a}\right)$.

\section{3 氮的输出量计算}

农业土地中输出的氮与农作物的产量具有正的相关关系, 作物的收获量越大, 氮的输出量也越多. 根 据每种农作物的产量及单位产量的氮的摄取量, 分别计算出它们的氮输出. 参照统计年鉴的作物分类, 在 将粮食作物、经济作物及其它作物三大类作物划分成 18 小类作物的基础上, 分别统计它们的氮输出量. 粮 食作物分 8 个小类, 其中谷物分 5 类, 豆类分 2 类, 剩下的 1 类为薯类, 5 类谷物分别是水稻、小麦、大麦及其 它麦、玉米、其它谷物,2 类豆类划分为大豆及其它豆. 经济植物及其它植物分油菜籽、其它油料、棉花、糖 料、药材、蔬菜、果用瓜、水果、茶叶、虫茧、饲料草及秸秆、花卉园艺等 12 小类. 
主要农作物氮摄取量的系数为: 谷物取值 $17-25 \mathrm{~kg} / \mathrm{t} \mathrm{N}$, 豆类取 $40.8-50 \mathrm{~kg} / \mathrm{t} \mathrm{N}$, 薯类取 $2.5 \mathrm{~kg} / \mathrm{t} \mathrm{N}$, 油 料植物取 $35 \mathrm{~kg} / \mathrm{t} \mathrm{N}$, 棉花 (籽) 取 $30 \mathrm{~kg} / \mathrm{t} \mathrm{N}$, 糖料(甘蔗及甜菜) 取 $3 \mathrm{~kg} / \mathrm{t} \mathrm{N}$, 蔬菜取 $3.5 \mathrm{~kg} / \mathrm{t} \mathrm{N}$, 果用瓜及水果 取平均值 $3.5 \mathrm{~kg} / \mathrm{t} \mathrm{N}$.

\section{2 计算结果}

\section{1 研究区域概况}

太湖是典型的河网平原湖泊,特点是出人湖河道多, 且流向顺逆不定. 许多河道既是入湖河道, 又是出 湖河道, 因此, 上游集水流域难以准确界定. 根据各人湖河道每年净人太湖水量以及太湖沿岸地区的地势 特点, 本研究将望虞河以西、太湖东部水文巡测线以西以及东苕溪导流以西的太湖流域定义的太湖上游流 域. 流域范围涉及无锡、常州、镇江、南京、苏州、湖州、杭州及宣城等市共 348 个乡镇(含独立林场或农场), 流域总面积 $18885 \mathrm{~km}^{2}$ (不含太湖面积 $2344 \mathrm{~km}^{2}$ ), 占太湖流域总面积的 $50.8 \%$, 其中, 农业用地面积为 75.3 $\times 10^{3} \mathrm{~km}^{2}$, 占太湖流域总的农业用地面积的 $49.5 \%$, 流域人口 1359.8 万人, 其中,农业人口 817.6 万人, 流 域人口占太湖流域总人口的 $37.0 \%$. 在农业用地中,耕地占 $89.2 \%$,桑、果、茶等园地占 $10.8 \%$.

根据上游的水系及地势特点, 参照太湖流域的水利分区 ${ }^{[6]}$, 基于数字地形模型, 将上游流域划分为 7 个 子区域(或子流域).表 1 是 GIS 计算得到的各个子区域的基本情况. 在各个子区域中,武澄锡地区的农业 人口密度最高, 达 756 人 $/ \mathrm{km}^{2}$, 东苕溪流域最低, 为 213 人 $/ \mathrm{km}^{2}$. 同时, 这两个地区也是农业用地比例最高 及最低的两个地区, 分别占各区土地总面积的 $56.5 \%$ 及 $15.8 \%$.

表 1 上游子区域的主要特点

Tab. 1 Main features of the sub - basins

\begin{tabular}{cccccccc}
\hline \multirow{2}{*}{ 子区域 } & 面积 & 总人口 & 农业人口 & \multicolumn{4}{c}{ 农业用地 $\left(\mathrm{hm}^{2}\right)$} \\
\cline { 7 - 8 } & $\left(\mathrm{km}^{2}\right)$ & $($ 人) & $($ 人) & 合计 & 水田 & 旱地 & 园地 \\
\hline 东芳溪流域 & 2285 & 675234 & 487426 & 36064 & 24705 & 3502 & 7858 \\
西苦溪流域 & 3662 & 1188684 & 912852 & 93928 & 67426 & 8387 & 18116 \\
宜溧河流域 & 3089 & 1657134 & 1064165 & 142574 & 101879 & 19802 & 20893 \\
洮滆湖以北片区域 & 4686 & 3572426 & 2250376 & 224829 & 173801 & 36295 & 14733 \\
武澄锡低片区域 & 2153 & 3697220 & 1626857 & 101257 & 77472 & 18021 & 5764 \\
澄锡虞片区域 & 1730 & 1731074 & 1141556 & 97752 & 79962 & 15573 & 2217 \\
太湖东南沿岸区域 & 1281 & 1076208 & 692726 & 57102 & 41016 & 4183 & 11903 \\
合计 & 18885 & 13597980 & 8175958 & 753505 & 566260 & 105762 & 81483 \\
\hline
\end{tabular}

\section{2 计算结果及误差分析}

2.2 .1 氮的输入、输出及剩余总量及其构成 全区域氮的输人总量、输出总量及剩余总量分别为 301.2 $\times 10^{3} \mathrm{t} / \mathrm{a} 、 166.4 \times 10^{3} \mathrm{t} / \mathrm{a}$ 及 $134.8 \times 10^{3} \mathrm{t} / \mathrm{a}$. 洮滆湖以北地区因其农业土地面积大, 输人、输出及剩余总量 也大, 分别为 $93.9 \times 10^{3} \mathrm{t} / \mathrm{a} 、 49.5 \times 10^{3} \mathrm{t} / \mathrm{a} 、 44.5 \times 10^{3} \mathrm{t} / \mathrm{a}$, 占太湖上游流域输人、输出及剩余总量的 $31.2 \%$ 、 $29.7 \%$ 及 $33.0 \%$ 。宜溧河流域、澄锡虞片及武澄锡低片的剩余量为 $22.0 \times 10^{3} \mathrm{t} / \mathrm{a}$ 左右, 最大 $23.0 \times 10^{3} \mathrm{t} / \mathrm{a}$, 最小 $20.8 \times 10^{3} \mathrm{t} / \mathrm{a}$. 东苕溪流域的输人、输出及剩余总量均最小, 分别为 $13.2 \times 10^{3} \mathrm{t} / \mathrm{a} 、 8.8 \times 10^{3} \mathrm{t} / \mathrm{a}$ 及 4.4 $\times 10^{3} \mathrm{t} / \mathrm{a}$, 仅分别占上游流域的 $4.4 \% 、 5.3 \%$ 及 $3.1 \%$. 从输出效率 (输出量占输人量的比例)看,东、西苕溪 流域均较高, 达 $65 \%$ 以上,其它区域较为接近, 在 $52.5 \%-53.6 \%$ 之间.

在研究区域各个输人项中, 人工肥料所占比例最高,达 $68.1 \%$, 人畜粪便 (净输人) 占 $19.5 \%$, 其余 $12.4 \%$ 来源于生物固氮、大气降氮及植物种子带人的氮. 在输出项目中, 农产品收获的氮占 $71.9 \%$, 草料及 秸秆等收获的氮占 $28.1 \%$.

2.2 .2 单位农业土地面积的氮剩余量及其空间变化特点 整个区域单位农业土地面积的剩余量为 178.9 $\mathrm{kg} /\left(\mathrm{hm}^{2} \cdot \mathrm{a}\right)$. 武澄锡低片、锡澄虞片、洮滆湖以北片及太湖东南沿岸片等区域的氮的剩余量较大, 分别 
$221.1 、 212.6 、 197.8$ 及 $193.8 \mathrm{~kg} /\left(\mathrm{hm}^{2} \cdot \mathrm{a}\right)$; 宜溧河、东苕溪及西苕溪等流域的剩余量较低, 分别为 161.5 、 123.5 及 $91.5 \mathrm{~kg} /\left(\mathrm{hm}^{2} \cdot \mathrm{a}\right)$. 从各乡镇的单位农业土地面积的剩余量来看, 流域北部的剩余量显著高于流 域西部及南部,另外,城市郊区的一些乡镇往往具有很高的剩余量.

氮剩余量空间差异的影响因素很多,不仅与农业发展水平有关,还与城镇化程度、农业土壤结构、农业 种植结构及农业化肥的施用量及施用方式有关. 南部地区的农业发展水平高, 农业人口权重大,城镇化程 度低, 农民的经济收人主要来源于农业收人. 近年来, 随着农业税收制度的改革, 农民的积极性更加高涨. 农民通过减少化肥使用, 提高有机肥料的利用率, 达到节约农业成本的目的. 此外,这些地区茶园面积较 大, 近些年来, 广泛推广少施化肥、多施有机肥的生态茶园, 提高了人畜粪便的氮利用率. 这些因素是导致 南部地区氮输人效率提高的主要原因. 而在太湖北部地区,农业人口权重小, 城镇化程度高, 农民的经济收 人不仅仅依赖农业收人,农民为了减少农业生产时间,大量使用无机肥料,从而导致人畜粪便等有机肥料的 氮素浪费.

2.2.3 结果的误差分析 受区域农业发展水平的影响, 区域农业土地中氮的平衡规律比较复杂. 利用详实 并且准确的区域农业数据,能够比较正确地揭示氮输人、氮输出及氮剩余的空间变化规律. 本研究在采用 区域统计年鉴的同时, 还借鉴农业部门的调查数据, 不足的数据还通过样本抽查进行获取, 因此, 本研究的 基础数据比较可靠, 得到的研究结果也与实际情况比较接近. 计算误差可能存在于以下几个方面:

(1) 工业肥料的氮输人量采用的是实际施氮量扣除平均挥发量的数值,但是,受各地地形、气候差异及 施肥方式不同的影响, 实际输人量可能与计算中采用的数值不完全一致. 假设实际量在现状值的 $\pm 5 \%$ 范 围内变化,那么,全区域平均的氮剩余量在 $179 \pm 15 \mathrm{~kg} /\left(\mathrm{hm}^{2} \cdot \mathrm{a}\right)$ 范围之内变动.

(2) 受各地人类生活水平及动物饲料供给量的影响,人及动物的排氮系数在各个地区存在差异. 采用 统一的折算系数会对结果产生一定影响. 另一方面, 人畜粪便挥发量的计算误差也对结果产生一定影响. 利用世界各地人类及各类动物的最大、最小排氮系数及粪便的最大、最小挥发系数, 经模型测试, 人畜粪便 净输人量的最大可能误差为 $\pm 8 \%$, 平均氮剩余量的最大可能误差为 $\pm 4 \%$.

(3) 各地区种植了一定数量的固氮豆科绿肥植物, 如紫云英及黄花苜宿等, 通过这些植物的固氮, 增加 土壤的氮输人. 由于没有这些植物的详细收获数据, 没有考虑这些植物的固氮量. 假定这些植物的种植面 积占各地总绿肥植物种植面积的 $50 \%$, 按每公顷产 $25 \mathrm{t}$ 鲜草计算, 通过这些植物固氮, 全区域单位农业用地 面积的氮输人及剩余量比原结果约高 $1 \%$ 左右.

（4）根据调查, 目前仅在部分地区使用了少量的河湖淤泥及城市固废作为农田肥料,假设每公顷农业 土地使用 $2 \mathrm{t}$ 的淤泥, 土地中氮的输人量将增加 $3 \mathrm{~kg} /\left(\mathrm{hm}^{2} \cdot \mathrm{a}\right)$ 左右.

(5) 农作物氮的摄取系数大多取自国外的研究成果, 国外在该方面的研究成果较多, 且各种植物摄取 系数的变化幅度较小, 各系数的高值及低值对输出量及剩余量计算结果的影响(仅为 $1 \%-2 \%$ )较小, 可以 忽略.

（6）区域内有少量的花卉园艺种植面积,根据各县的花卉园艺的栽种面积,按最大可能耗氮量 $700 \mathrm{~kg} /$ $\left(\mathrm{hm}^{2} \cdot \mathrm{a}\right)$ 计算,经重新计算,全区平均氮剩余量将比现值减少 $1.6 \mathrm{~kg} /\left(\mathrm{hm}^{2} \cdot \mathrm{a}\right)$.

(7) 草料及秸秆氮输出量的计算误差也对氮剩余量的计算结果具有一定影响. 本研究直接采用国外 的方法进行计算 ${ }^{[1]}$. 据文献分析, 计算结果的可能误差大约为 $5 \%$ 左右.

\section{3 氮剩余的演变趋势及其对太湖富营养化的影响}

基于区域南部长兴县的完整系列农业数据集及 1995 年以来其它各县的农业数据,推算上游地区农业 土地氮剩余的长期变化. 在此基础上, 分析和探讨氮剩余量的长期变化对太湖富营养化的影响.

\section{1 典型区域氮剩余量的时间变化趋势分析}

选择太湖南部的长兴县为典型研究区域,利用 $1952-2002$ 年间的长系列农业数据,计算出各个年份的 氮的输人量、输出量及剩余量. 计算结果表明, 在 50 年代期间, 氮的输人量与输出量均出现增加趋势, 但两 者的增速大体相当, 因此, 剩余量的增加趋势几乎没有, 基本上在 5.1-21.4 kg/ $\left(\mathrm{hm}^{2} \cdot \mathrm{a}\right)$ 之间波动, 平均输 人效率超过 $80 \%$. 在 60 年代期间, 输人量的增速大于输出量的增速, 因而导致剩余量以平均每年约 4.0 
$\mathrm{kg} /\left(\mathrm{hm}^{2} \cdot \mathrm{a}\right)$ 的速度增加. 在 70 年代前期, 输人量及输出量呈现同步快速增长, 而剩余量增长缓慢, 但到 70 年代后期, 三者均出现快速增长, 剩余量从 1975 年的 $50.1 \mathrm{~kg} /\left(\mathrm{hm}^{2} \cdot \mathrm{a}\right)$ 增加至 1980 年的 $131.9 \mathrm{~kg} /\left(\mathrm{hm}^{2}\right.$. a). 到了 80 年代, 三者总体变化趋势基本一致,但是变化过程却存在很大差异: 输人量基本上延续了 70 年 代后期的增加趋势, 仍然快速增长, 但输出量增速却减缓, 并出现波动; 受输人、输出两要素的综合影响, 剩 余量出现剧烈波动. 在 90 年代期间, 三者均在高位出现剧烈波动, 输人量及剩余量的最大值分别是最小值 的 2.1 及 7.2 倍.

典型区域氮剩余量的变化趋势不仅与太湖流域其它县市的变化趋势较为一致 (共计算 9 个县), 也与 全国的趋势比较一致. 为此, 利用典型区域的变化曲线, 并参照各县历年的化肥使用量、农业土地面积变化 以及粮油棉等主要农作物的产量,推算整个研究区的剩余量 (1995 年以后的氮剩余为模型计算结果). 为 了滤去短期的波动影响,仅统计 10 年期间的平均值 (表 2).

从表 2 可以看出, 在上世纪 50 年代期间, 平均剩余量仅为 $22.3 \mathrm{~kg} /\left(\mathrm{hm}^{2} \cdot \mathrm{a}\right)$, 而到 60 年代期间, 已经 增至 $45.4 \mathrm{~kg} /\left(\mathrm{hm}^{2} \cdot \mathrm{a}\right)$, 平均每年递增 $2.0 \mathrm{~kg} /\left(\mathrm{hm}^{2} \cdot \mathrm{a}\right)$ 左右, 在 60 年代至 70 年代期间, 平均每年递增 3.0 $\mathrm{kg} /\left(\mathrm{hm}^{2} \cdot \mathrm{a}\right)$ 左右, 到了 80 年代期间, 增幅显著加大, 达到每年 $10.0 \mathrm{~kg} /\left(\mathrm{hm}^{2} \cdot \mathrm{a}\right)$ 左右, 到了 90 年代期间, 增幅减小, 为每年 $3.0 \mathrm{~kg} /\left(\mathrm{hm}^{2} \cdot \mathrm{a}\right)$ 左右.

表 2 太湖上游地区上世纪 50 年代以来单位农业面积氮的输人、输出及剩余量的估算结果

Tab. 2 Estimation of nitrogen inputs, outputs and surpluses per hectare agricultural land in each decade

\begin{tabular}{ccccc}
\hline 年代 & $\begin{array}{c}\text { 平均输人量 } \\
\left(\mathrm{kg} / \mathrm{hm}^{2} \cdot \mathrm{a}\right)\end{array}$ & $\begin{array}{c}\text { 平均输出量 } \\
\left(\mathrm{kg} / \mathrm{hm}^{2} \cdot \mathrm{a}\right)\end{array}$ & $\begin{array}{c}\text { 平均剩余量 } \\
\left(\mathrm{kg} / \mathrm{hm}^{2} \cdot \mathrm{a}\right)\end{array}$ & $\begin{array}{c}\text { 平均输人效率 } \\
(\%)\end{array}$ \\
\hline $1950 \mathrm{~s}$ & 87.2 & 64.9 & 22.3 & 74 \\
$1960 \mathrm{~s}$ & 147.5 & 102.0 & 45.4 & 69 \\
$1970 \mathrm{~s}$ & 245.8 & 171.6 & 74.2 & 69 \\
$1980 \mathrm{~s}$ & 373.1 & 208.3 & 164.8 & 55 \\
$1990 \mathrm{~s}$ & 435.3 & 233.7 & 201.6 & 53 \\
\hline
\end{tabular}

\section{2 氮剩余量的长期变化对太湖富营养化影响的初步分析}

农田中剩余的氮需要经过吸附与解吸、沉淀与截留、迁移与转化以及复杂的水文输运过程, 才能排入河 流系统, 形成氮的排放量. 根据国外的研究, 剩余量与面源的排放量之间存在着很好的相关关系. 因此, 根据 氮剩余量的变化趋势也能基本揭示湖泊富营养化的演化规律.

据有关研究 ${ }^{[7]}$, 最近几十年来, 太湖的富营养 化趋势十分明显. 图 1 是上游地区农业土地中氮剩 余的长期变化与太湖水体中氮浓度的长期变化的 关系. 从中可以看出, TIN 及 $\mathrm{TN}$ 与农业土地的氮剩 余存在着明显的正相关关系. 在上世纪 60 年代初 期, 太湖上游农业土地的氮剩余量很低, 仅为 31.6 $\mathrm{kg} /\left(\mathrm{hm}^{2} \cdot \mathrm{a}\right)$, 而此时太湖的 TIN 也很低, 仅为 0.05 $\mathrm{mg} / \mathrm{L}$; 到 1981 年, 氮剩余量升至 $139.7 \mathrm{~kg} /\left(\mathrm{hm}^{2}\right.$. a), 比 1960 年增加了 4.4 倍, TIN 升至 $0.894 \mathrm{mg} / \mathrm{L}$, 比 1960 年增加了 17.9 倍; 在 1995 年, 氮剩余量达 到最高, 为 $209.8 \mathrm{~kg} /\left(\mathrm{hm}^{2} \cdot \mathrm{a}\right)$, $\mathrm{TN}$ 也达到最高, 为 $3.14 \mathrm{mg} / \mathrm{L}$, 两者分别是 1981 年的 1.5 及 1.6 倍. 氮 剩余与 TN 及 TIN 的相关系数 $\left(R^{2}\right)$ 分别为 0.96 、 0.78 . 由此可以推断, 太湖上游农业土地中的氮剩

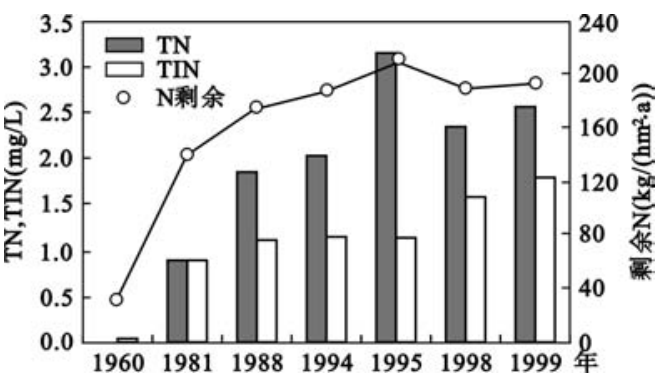

图 1 上游农业土地的氮剩余以及太湖 TN、TIN 含量的历史变化

Fig. 1 Historical changes of nitrogen surpluses in the upstream agricultural area of the Taihu Lake 余对太湖的富营养化演化具有非常重要的影响. 由于太湖的富营养化趋势不仅受区域农业土地氮排放的 
影响, 还与工业点源、生活废水排放有关. 各个影响因子的贡献率如何及不同子区域的贡献权重如何, 仍需 进一步研究.

\section{4 结论}

在 2002 年期间,太湖上游地区农业土地的氮的平均剩余量为 $178.9 \mathrm{~kg} /\left(\mathrm{hm}^{2} \cdot \mathrm{a}\right)$. 东苕溪流域、西苕 溪流域、宜溧河流域、武澄锡低片区域、锡澄虞片区域、洮滆湖以北区域及太湖东南沿岸区域等 7 个子区域 的剩余量的空间差异明显,最大剩余量达到 $221.1 \mathrm{~kg} /\left(\mathrm{hm}^{2} \cdot \mathrm{a}\right)$, 最小仅为 $91.5 \mathrm{~kg} /\left(\mathrm{hm}^{2} \cdot \mathrm{a}\right)$.

农业土地氮剩余的空间差异的影响因素很多,不仅与区域农业发展水平有关,还与城镇化水平、土壤结 构、农业种植结构及农业化肥的施用量及施用方式有关.

太湖上游农业土地中氮剩余的长期变化与太湖水体中氮浓度的长期变化之间具有很好的相关关系. 因 此,氮剩余量的变化趋势对太湖的富营养化演化产生了非常重要的影响.

与上世纪 90 年代中后期相比,太湖上游农业土地的氮的剩余量虽然有所下降,但是, 下降的幅度并不 是很多. 这是为何太湖上游地区在工业点源得到控制, 而湖泊水质仍然没有得到根本好转的一个主要 原因.

为了防止太湖富营养化趋势的加重,除对上游地区的点源排放进行控制外,还必须加强农业土地的氮 素管理. 充分利用人畜粪便等有机肥料, 减少无机化肥的使用. 借助国外的营养盐管理经验, 在保证农作物 丰产丰收的前提下,将农业土地的氮剩余量控制在 $80 \mathrm{~kg} /\left(\mathrm{hm}^{2} \cdot \mathrm{a}\right)$ 以下.

\section{5 参考文献}

[1] Behrendt H, Huber P, Kornmilch M, et al, Nutrient Emissions into river basins of Germany. UBA - Texte $2000,23 / 00: 1-266$.

[2] Behrendt H, Dannowski R. Nutrients and heavy metals in the Odra River Systems. Berlin: Weiensee Verlag, $2005: 128-133$.

[3] Somloydy L, Brunner P H, Kroi H. Nutrient balances for Danube countries: a strategic analysis. Wat Sci Tech,1999,40(10): $9-16$.

[4] Zessner M,Gils J. Nutrient fluxes from the Danube basin to the Black Sea. Wat Sci Tech,1999,46(8):9 17.

[5] OECD. OECD national soil surface nutrient balances: 1985 to 1996-explanatory notes. Paris, OECD Secretary $1997: 1-16$.

[6] 中国科学院南京地理与湖泊研究所, 水利部太湖流域管理局. 太湖流域自然资源地图集. 北京:科学 出版社, $1991: 12$.

[7] 秦伯强等. 太湖水环境演化. 北京:科学出版社,2004:19 